\title{
The attitudes of Korean physicians toward emergency contraceptive pills: regarding women's access and rescheduling
}

\author{
Eun Sil Lee, Chong A Lee, Jee Hee Lee, Bo Ra Park, Imsoon Lee \\ Department of Obstetrics and Gynecology, Soonchunhyang University Seoul Hospital, Soonchunhyang University College of Medicine, Seoul, Korea
}

\section{Objective}

This study investigated the attitude of Korean physicians toward women's access to emergency contraceptive pills (ECPs) and the reclassification of ECP to a behind-the-counter (BTC) drug.

\section{Methods}

This study involved 946 physicians who had prescribed ECP in South Korea. The written questionnaires were completed by obstetricians and gynecologists, family physicians, internal medicine doctors, and pediatricians.

\section{Results}

Regarding the barriers limiting women's access to ECP, $24.8 \%$ of physicians responded that women lacked information about ECP and $22.5 \%$ felt that women were likely to be emotionally burdened by visits to clinics or hospitals to obtain ECP prescriptions. Ninety-two percent of physicians responded that ECP should remain a prescription drug while $6.1 \%$ stated preferences for a switch to a BTC drug. Physicians who opposed the switch were concerned about the potential abuse of ECP. In order to prevent ECP abuse, the most important factor to be considered was education on contraception.

\section{Conclusion}

A majority of Korean physicians opposed the reclassification of ECP to a BTC drug owing to their belief in increasing the role of educational initiatives about contraception and contraceptive practices before improving the access to ECP. This study is also of the opinion that contraceptive education for youth and adults in Korea should be more realistic and active, with an emphasis on regular contraception use before reclassification. Furthermore, we believe that efforts are needed to ensure accuracy of information on contraception to facilitate women's access to ECP.

Keywords: Emergency contraceptive pill; Barriers; Women's access; Rescheduling

\section{Introduction}

Among the countries in the Organization for Economic Cooperation and Development, South Korea has indicated a relatively low oral contraceptive usage rate of $3 \%$ and a high artificial abortion rate $[1,2]$. Although artificial abortion is legally prohibited in Korea, $26 \%$ of married women have undergone artificial abortion. Among unmarried women, $7 \%$ experienced pregnancy and $91 \%$ of the women who had experienced pregnancy underwent artificial abortion [3]. It should be noted that the contraceptive practice rate among sexually active middle and high school students is as low as $39 \%$ [4]. On the other hand, the abuse of emergency contra-
Received: 2018.08.30. Revised: 2018.10.22. Accepted: 2018.10.23. Corresponding author: Imsoon Lee

Department of Obstetrics and Gynecology, Soonchunhyang University Seoul Hospital, Soonchunhyang University College of Medicine, 59 Daesagwan-ro, Yongsan-gu, Seoul 04401, Korea E-mail: elsee165@gmail.com https://orcid.org/0000-0002-1032-6608

Articles published in Obstet Gynecol Sci are open-access, distributed under the terms of the Creative Commons Attribution Non-Commercial License (http://creativecommons. org/licenses/by-nc/3.0/) which permits unrestricted non-commercial use, distribution, and reproduction in any medium, provided the original work is properly cited.

Copyright ( 2019 Korean Society of Obstetrics and Gynecology 


\section{Obstetrics \& Gynecology Science}

Vol. 62, No. 3, 2019

ceptive pills (ECPS), involving the intake of the pill more than twice a month, increased by 2.3 times from 2012 to 2015 and by 2.5 times in teenagers over the course of 3 years [5]. This indicates that ECP abuse without regular contraception is still an issue of concern in South Korea.

The availability of ECP as either over-the-counter/behindthe-counter (BTC) or as a prescription drug has been one of the most controversial issues in South Korea. While most of the oral contraceptives are classified as BTC, all ECP single agents have been classified as prescription-only products since their first introduction in South Korea in 2001. Since then, despite attempts to reclassify the ECP to BTC, it is still available through prescription-only in South Korea, owing to strong religious and social reasons as well as medical opinion against the reclassification. Conflicting opinions have been issued regarding the need for a prescription to obtain ECP. The Korean Association of Obstetricians \& Gynecologists opposed the reclassification of ECP stating that regular contraception would be less favored if ECP was to be converted to a BTC drug, as the contraceptive usage rate of Koreans is already low [6].

However, there have been no studies that directly investigated individual physicians for their opinions on the reclassification of ECP. Therefore, this study investigated the attitude of Korean physicians regarding women's access to ECPs and the reclassification of ECP to a BTC drug.

\section{Materials and methods}

This study was conducted between April 2014 and November 2015 as a part of a research investigation into the utilization patterns, knowledge, perceptions, and attitudes of Korean women on contraceptives, organized by the National Institute of Food and Drug Safety Evaluation [7].

This survey was conducted among physicians who had prescribed ECP in South Korea. The draft questionnaire for the survey was developed after reviewing the relevant literature and was modified by 7 gynecologists. A preliminary survey of 38 physicians (30 obstetric \& gynecologists and 8 non-obstetric \& gynecologic physicians) was conducted to solicit opinions related to its comprehensibility. After collecting several comments from 38 physicians and appropriate reviews, a final questionnaire was created (Supplementary data 1). The written questionnaire was completed voluntarily by physicians attending 5 medical symposia. A few questionnaires were mailed to private clinics and hospitals. Completed questionnaires were mailed or faxed back. A total of 975 physicians responded to the questionnaire and 29 cases involving inadequate responses or uninformed respondents were excluded. Of the physicians who completed the questionnaire, $74.4 \%$ were obstetricians and gynecologists, $7.8 \%$ were family physicians, $7.4 \%$ practiced internal medicine, and $2.0 \%$ were pediatricians.

\section{Results}

Each month, Korean physicians prescribed ECP to an average of $14.9 \pm 23.9$ women during the past year (between December 2013 and November 2014). The number of women who were prescribed for ECP was highest among the 19-24 age group (51.6\%), followed by the 25-29 (25.1\%), the 30-39 $(9.6 \%)$, and the $40-49(0.6 \%)$ age groups. Women under the age of 18 constituted $5.7 \%$ (Fig. 1).

In terms of the duration following sexual intercourse until the visit to the clinic or hospital for ECP prescription, 63.3\% of physicians answered that it was within 24 hours and $97 \%$ of physicians replied that it was within 72 hours (Fig. 2).

The most commonly prescribed emergency contraceptive method by the physicians surveyed was levonorgestrel (LNG) alone, accounting for $66 \%$ of all prescriptions, followed by ulipristal acetate (UPA; 30.0\%). The Yuzpe method and copper intrauterine device were most frequently prescribed by $2.1 \%$ and $0.2 \%$ of physicians, respectively.

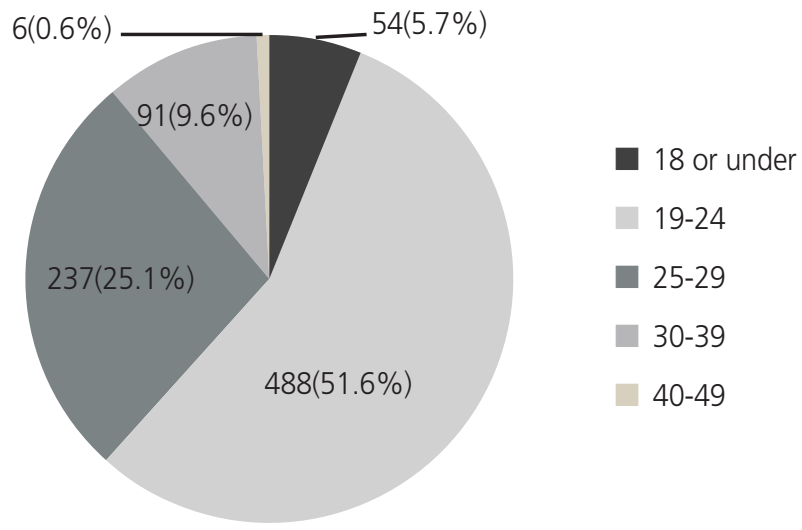

Fig. 1. Age group of women with the most frequent emergency contraceptive pill prescription rate $(n=946)$. 


\section{Obstetrics \& Gynecology Science}

Eun Sil Lee, et al. Attitudes to rescheduling ECP in Korea

\section{Physicians' awareness of emergency contraceptive pill access among women and barriers limiting women's access}

Twenty-point four percent of physicians reported that it was very easy for women to access ECP, and $23.3 \%$ of physicians stated that it was somewhat easy. However, $15.0 \%$ and $2.1 \%$ of physicians responded that it was somewhat difficult or very difficult to obtain ECP, respectively (Table 1). Regarding the barriers limiting women's access to ECP, $24.8 \%$ of physicians stated that women lacked information about ECP and $22.5 \%$ of physicians answered that women were likely to be emotionally burdened by a visit to a clinic or hospital to obtain ECP prescription. Another $12.2 \%$ of physicians responded that women were concerned about the recording of their sexual privacy (Table 2). A request for ECP prescription without recording personal information was made by patients to $51 \%$ of the physicians.

\section{Physician's opinions about the switch of emergency contraceptive pill from a prescription to a behind- the-counter drug}

Our survey indicated that $92 \%$ of physicians preferred to maintain ECP as a prescription drug while $6.1 \%$ desired a switch to a BTC drug. The reasons why physicians opposed the switch of ECP to a BTC drug were because of concerns about its potential abuse (76.7\%), followed by the need for contraceptive education and counseling (10.6\%), safety issues $(7.7 \%)$, concerns about an increase in undesirable sexual practices (3.2\%), and concerns about an increase in unprotected sex $(0.98 \%)$ (Table 3). Conversely, among the

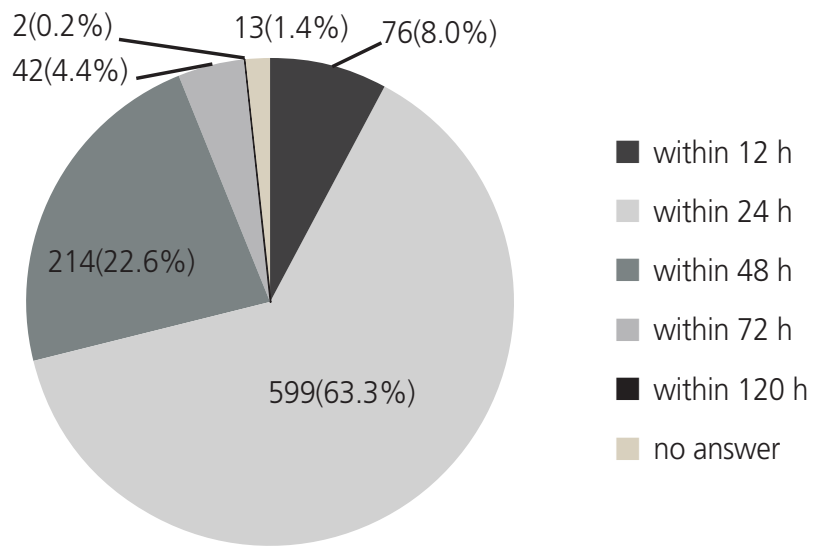

Fig. 2. Time lapse between sexual intercourse and emergency contraceptive pill prescription $(n=946)$. physicians who preferred the reclassification of ECP to a BTC drug, the most common reasons were women's rights to choose contraception (55.2\%), followed by easy access to ECPs (19.0\%), minimal side effects (8.6\%), decrease in medical expenses $(6.9 \%)$, reduced risk of unwanted pregnancies $(6.9 \%)$, and protection of sexual privacy (1.7\%).

\section{Prevention of emergency contraceptive pill abuse} The abuse of ECP is defined by the regular use of ECPs each time women engaged in unprotected sex instead of regular

Table 1. Physicians' awareness of emergency contraceptive pill access among women $(n=946)$

\begin{tabular}{lc}
\hline Physicians' awareness & No. of physicians (\%) \\
\hline Very easy & $193(20.4)$ \\
Somewhat easy & $220(23.3)$ \\
Neutral & $365(38.6)$ \\
Somewhat difficult & $142(15.0)$ \\
Very difficult & $20(2.1)$ \\
No answer & $6(0.6)$ \\
\hline
\end{tabular}

Table 2. Barriers limiting women's access to emergency contraceptive pill $(n=946)$

\begin{tabular}{lc}
\hline Barrier & $\begin{array}{c}\text { No. of } \\
\text { physicians (\%) }\end{array}$ \\
\hline Women's lack of information & $235(24.8)$ \\
Emotional burden by visit a clinic or a hospital & $213(22.5)$ \\
Concerns about sexual privacy & $115(12.2)$ \\
Concerns about side effects & $60(6.3)$ \\
Inconvenience & $18(1.9)$ \\
Cost & $10(1.1)$ \\
Others & $2(0.2)$
\end{tabular}

Table 3. The reasons for opposing the switch of emergency contraceptive pill (ECP) to a behind-the-counter drug $(n=870)$

\begin{tabular}{lc}
\hline Reason & $\begin{array}{c}\text { No. of } \\
\text { physicians (\%) }\end{array}$ \\
\hline Concern about abuse of ECP & $667(73.7)$ \\
$\begin{array}{l}\text { Need for contraceptive education and } \\
\text { counseling }\end{array}$ & $92(10.6)$ \\
Safety issue & $67(7.7)$ \\
Concern about increase in undesirable sex & $28(3.2)$ \\
Concern about increase in unprotected sex & $8(1.0))$ \\
Others & $1(0.1)$ \\
\hline
\end{tabular}




\section{Obstetrics \& Gynecology Science}

Vol. 62, No. 3, 2019

contraception.

In order to prevent ECP abuse, physicians believed that the most important factors to be considered were education on contraception (79.0\%), restriction of repetitive prescriptions within the same menstrual cycle $(7.7 \%)$, improved accessibility $(5.3 \%)$, and a price increase of ECP $(0.7 \%)$ (Table 4$)$.

\section{Discussion}

Emergency contraception refers to the use of drugs or copper intrauterine devices to prevent pregnancy shortly after unprotected intercourse [8]. Several interventions have been developed for emergency contraception and their effectiveness as well as safety are well known [9-11]. LNG only and UPA pills are available over- or behind-the counter without a prescription in a significant number of countries, based on their relative safety profile and evidence suggesting their role in effectively delaying ovulation [12]. However, ECPs are only available through prescription in South Korea. In August 2012, the Korean Ministry of Food and Drug Safety attempted to repeal an existing policy and reclassify ECP to approve ECP's BTC availability; however, the ministry abandoned the reclassification following an intense debate among the groups involved [13]. The Korean Association of Obstetricians and Gynecologists also opposed the switch to BTC [6]. However, no reported survey of Korean physicians, including individual gynecologists, was available.

The results of this study showed that almost every physician prescribed ECP within 72 hours following unprotected intercourse and LNG was the most commonly prescribed emergency contraception method by Korean physicians. This

Table 4. Most important factors for prevention of emergency contraceptive pill abuse

\begin{tabular}{lc}
\hline Factor & $\begin{array}{c}\text { No. of } \\
\text { physicians (\%) }\end{array}$ \\
\hline Contraceptive education & $747(79.0)$ \\
$\begin{array}{l}\text { Restriction of repetitive prescription within the } \\
\text { same menstrual cycle }\end{array}$ & $73(7.7)$ \\
Improved accessibility & $50(5.3)$ \\
Price increase & $7(0.7)$ \\
Others & $2(0.2)$ \\
No answer & $67(7.1)$ \\
\hline
\end{tabular}

finding is in contrast to the report indicating that two-thirds of all ECPs sold in Germany were UPA since the availability of ECP as a BTC drug in March 2015 [14]. A majority (92\%) of Korean physicians preferred to maintain ECP as a prescription drug to prevent its potential abuse and to promote counseling and education for regular contraception. The Korean Association of Obstetricians and Gynecologists also currently recommends that ECP should be converted to BTC only after Korean women are educated on contraceptive usage because the rate of oral contraceptive consumption is relatively low in Korean women. In fact, despite the fact that oral contraceptive usage among Korean women has steadily increased from $2.1 \%$ in 2010 to $2.8 \%$ in 2014, it is still relatively low compared with the UK (21.6\%), Canada (16.3\%), Belgium (38.8\%), Australia (19.9\%), and USA (13.4\%) [15]. The rate of oral contraceptive pill use in Korean women is similar to that of Japanese (2.3\%), Malaysian (2.7\%), and Indonesian women (2.7\%) [16]. Japan and Indonesia still classify ECPs as a prescription drug [17], similar to Korea.

In a study of contraceptive practices involving Korean middle and high school adolescents, only $20-26 \%$ of the students who had engaged in sexual intercourse replied that they always practice contraception. On the other hand, $45-49 \%$ reported that they never used contraception at all [18]. In another report on contraception in Korean youth, Korean teenagers were most unlikely to use contraceptives, while contraceptive users were most likely to use condoms and only $3-4 \%$ of adolescents reported taking oral contraceptives. Among unmarried, sexually active young adults aged 20 and above, $13.4 \%$ of men and $6.7 \%$ of women experienced pregnancy. Of these individuals who had experienced pregnancy, $72.7 \%$ of men and $100 \%$ of women selected artificial abortion [19]. In a survey of 15- to 18-yearold girls who were exposed to oral contraceptives in South Korea, majority of them had been taught about condom usage but were ignorant about oral contraceptives and other contraceptive practices. They were not well informed about the options and methods of oral contraceptives and ECP, and often had false medical knowledge about oral contraceptives and ECP [20]. The rate of ECP use among adolescents was $0.98-1.3 \%$, which was much lower than condom use $(36.7 \%)$, withdrawal $(8.3 \%)$, and rhythm (2.6\%).

Korean physicians responded that contraceptive education (79.0\%) was the most important factor to be considered to prevent the abuse of ECP, followed by restriction of repetitive 


\section{Obstetrics \& Gynecology Science}

prescriptions within the same menstrual cycle (7.7\%).

Lack of information was the most common barrier restricting women's access to ECP. A survey of Korean women's awareness of ECPs found that Korean women, in spite of taking ECPs, were worried that ECPs induced serious side effects and were associated with fetal anomalies following pregnancy [21]. This suggests a negative and false perception about the safety of ECP and lack of information on the part of Korean women.

In addition to insufficient information, $22.5 \%$ of physicians recognized that there was a psychological issue with regards to women visiting clinics or hospitals to obtain ECP prescriptions. The fact that $51 \%$ of physicians had been asked to prescribe ECP without recording personal information, underscores the need for a policy to further improve ECP access in Korea. The fact that the survey indicates that $17 \%$ of physicians found ECP access difficult, suggests the need for greater and improved access.

This study suggests a need for practical and active education on contraception among youth and adults in Korea. The education is required to enhance proper awareness of regular and emergency contraception. Additionally, efforts are needed to ensure that women with accurate information on contraception can easily access ECP.

To the best of our knowledge, this is the first survey that evaluated the Korean physicians' attitude toward ECP regarding women's access and reclassification of ECP.

The study's limitation relates to its non-representative character in that the survey cannot be generalized to the entire physician community in South Korea, although it was conducted among approximately 1,000 physicians. Furthermore, since most of the subjects were obstetricians and gynecologists $(74.4 \%)$, it does not represent the opinion of other physicians. It is necessary to survey the broader physician population given that $37 \%$ of ECPs were prescribed by physicians who were not obstetricians or gynecologists [22]. Second, physicians' opinions about access and barriers to ECPs may differ from those of women in need of ECPs. Further studies are needed to identify the gaps between physicians and women. These efforts are expected to lower the barriers among women in need of contraception.

In conclusion, most Korean physicians opposed the reclassification of ECP to a BTC drug, due to their belief in increasing the role of educational initiatives about contraception and contraceptive practices, before improving the access to
ECP. Physicians stated that insufficient information about ECP and the emotional burden among women visiting clinics or hospitals acted as the biggest barriers in promoting access to ECP among women. This study suggests that contraceptive education for youth and adults in Korea should be more realistic and active, with an emphasis on regular contraception. Furthermore, efforts are needed to ensure accuracy of information on contraception, to facilitate women's access to ECP.

The majority of physicians were of the opinion that ECP should remain as a prescription drug because of concerns about its potential abuse. Before the reclassification, contraceptive education for youth and adults should be more realistic and active, with an emphasis on the importance of regular contraception. Furthermore, efforts are needed to ensure that women with accurate information can access ECPs conveniently without privacy concerns.

\section{Acknowledgements}

We thank Hye Bin Kim and Dani Choi for their excellent research assistance. This research was supported by National Institute of Food and Drug Safety Evaluation of Korea (grant number 14712-125).

\section{Conflict of interest}

No potential conflict of interest relevant to this article was reported.

\section{Ethical approval}

The study was approved by the Institutional Review Board of National Institute of Food and Drug Safety Evaluation and performed in accordance with the principles of the Declaration of Helsinki. Written informed consents were obtained.

\section{References}

1. Kim DS, Kim YT, Lee SY. Debates and implications on contraception and abortion policy: focusing on women's 


\section{Obstetrics \& Gynecology Science}

Vol. 62, No. 3, 2019

reproductive health right. Seoul: Korean Women's Development Institute; 2014.

2. Lee JH. Korea's contraceptive use rate of $3 \%$, 'the world's lowest' [Internet]. Daegu: Digital Economy; c2014 [cited 2014 Dec 8]. Available from: http://www. deconomic.co.kr/news/articleView.html/?idxno=5492.

3. Choi JS, Chae SM, Park E, Seo K. Policy issues on abortion in Korea. Seoul: Korea Institute for Health and Social Affairs; 2010.

4. Lee IS, Choi GY, Cha SH, Park HY, Lee JJ. A survey on the sexual behavior of adolescents in South Korea: the third survey in 2007. Korean J Obstet Gynecol 2010;53:5129.

5. Jun $\mathrm{MH}$. Teenager surge in emergency contraceptive pill [Internet]. Seoul: Yonhapnews; c2016 [cited 2016 Sep 23]. Available from: http://www.yonhapnews.co.kr/bulle tin/2016/09/23/0200000000AKR20160923039000017.

6. Lee MY. Premature discussion of emergency contraceptive reclassification [Internet]. Seoul: Kukmin Ilbo; c2011 [cited 2011 Aug 12]. Available from: http://news.kmib. co. kr/article/view. asp?arcid=1313167470\&amp;code=1 4131301\&amp;sid1=all.

7. Koo B, Lee IY, Lee IS, Chang MJ, Jung SY, Choi EM, et al. Research on the utilization patterns, knowledge, perceptions and attitudes of Korean women on contraceptives. Osong: Korean National Institute of Drug Safety Evaluation; 2015.

8. Shen J, Che Y, Showell E, Chen K, Cheng L. Interventions for emergency contraception. Cochrane Database Syst Rev 2017;8:CD001324.

9. Richardson AR, Maltz FN. Ulipristal acetate: review of the efficacy and safety of a newly approved agent for emergency contraception. Clin Ther 2012;34:24-36.

10. Gemzell-Danielsson K, Rabe T, Cheng L. Emergency contraception. Gynecol Endocrinol 2013;29 Suppl 1:1-14.

11. Lee JK, Schwarz EB. The safety of available and emerging options for emergency contraception. Expert Opin Drug Saf 2017;16:1163-71.

12. Gemzell-Damielsson K, Berger C, Lalitkumar PG. Mechanisms of action of oral emergency contraception. Gynecol Endocrinol 2014;30:685-7.
13. Min SJ. Getting a prescription for emergency contraception in Korea [Internet]. Seoul: Sisacast; c2016 [cited 2016 May 20]. Available from: http://www.sisacast.kr/ news/articleView.html?idxno=11659.

14. Kiechle M, Neuenfeldt M. Experience with oral emergency contraception since the OTC switch in Germany. Arch Gynecol Obstet 2017;295:651-60.

15. IQVIA. Oral contraceptive consumption volume: IMS sales audit as of Q4 MAT, IQVIA data [Internet]. Durham (NC): IQVIA; c2016 [cited 2016 Sep 23]. Available from: https://www.iqvia.com.

16. IQVIA. Oral contraceptive consumption volume: IMS MIDAS as of Q4 MAT, IQVIA data [Internet]. Durham (NC): IQVIA; c2016 [cited 2016 Sep 23]. Available from: https://www.iqvia.com.

17. International Consortium for Emergency Contraception. EC status and availability-countries with non-prescription access to EC, ICEC data [Internet]. New York (NY): International Consortium for Emergency Contraception; c2018 [cited 2018 May 11]. Available from: http://www. cecinfo.org/country-by-country-information/status-availabilitydatabase/countries-with-non-prescription accessto-ec.

18. Lee HJ, Kang HS. Rates and methods of contraception among Korean adolescents from 2007 to 2009. Korean J Women Health Nurs 2011;17:148-56.

19. Hwang SW, Chung CW. Contraception behavior and related factors in unmarried female and male. Korean J Women Health Nurs 2011;17:77-87.

20. Kim E, Lee I, Lee S. Study about the experience of the sex education and the perception of the contraceptive pill of the female adolescent. J Korean Bioethics Assoc 2016;17:53-74.

21. Kang HS. Perceptions of emergency contraceptive pills among young Korean women. Korean J Women Health Nurs 2006;12:124-31.

22. UBcare. Projected outpatient prescription volume from 2013 to 2017 [Internet]. Seoul: UBcare; c2018 [cited 2018 May 11]. Available from: https://www.ubcare. co.kr. 